\title{
Risk factors associated with renal crescentic formation in pediatric Henoch-Schönlein purpura nephritis: a retrospective cohort study
}

Yong-Rui Song ${ }^{1}$, Wan-Liang Guo ${ }^{1}$, Mao Sheng ${ }^{1}$, Qiang Lin², Xue-Ming Zhu ${ }^{3}$ and Xiao-Zhong Li ${ }^{*}$ (D)

\begin{abstract}
Background: The long-term prognosis of Henoch-Schönlein purpura (HSP) depends on the severity of renal involvement, and crescent formation is considered an important risk factor for poor prognosis of Henoch-Schönlein purpura nephritis (HSPN). The objective of this study was to evaluate factors affecting crescent formation in children with HSPN.

Methods: Demographic factors, clinical characteristics, and laboratory data of children with HSPN with or without crescents were retrospectively analyzed. Univariate and multivariate logistic regression analyses were used to determine the risk factors of crescent formation in HSPN.

Results: A total of 191 children with HSPN were enrolled in the study. There were 107 (56\%) males and 84 (44\%) females, with a median age of 7 years (range: 2 years-15 years). International Study of Kidney Disease in Children (ISKDC) grading was used to divide subjects into two groups: those without glomerular crescent formation (ISKDC grades I-II, $n=146$ cases) and those with glomerular crescent formation (ISKDC grades III-V, $n=45$ cases). Logistic regression analysis showed that higher urinary white blood cell $(\mathrm{WBC})$ count $(O R=3.300 ; 95 \% \mathrm{Cl}, 1.119-9.739 ; P=$ $0.0306)$ and higher urinary microalbumin/creatinine ratio $(A C R)(O R=25.053 ; 95 \% \mathrm{Cl}, 1.354-463.708 ; P=0.0305)$ were independent risk factors for the formation of crescents in HSPN. The area under the receiver operating characteristic curve of urinary WBC and ACR were 0.753 and 0.698 respectively, with the Hosmer and Lemeshow goodness-of-fit test $(P=0.0669, P>0.05)$.
\end{abstract}

Conclusion: These results suggest that higher urinary WBC count and ACR should be strictly monitored for children with HSPN. Adequate clinical intervention for these risk factors may limit or prevent renal crescent formation.

Keywords: Risk factors, Crescent formation, Henoch-Schönlein purpura nephritis, HSPN

\footnotetext{
* Correspondence: xiaozhonglicn@yeah.net

${ }^{2}$ Department of Nephrology and Immunology, Children's Hospital of Soochow University, 303 Jingde Road, Suzhou 215003, Jiangsu, China Full list of author information is available at the end of the article
}

(c) The Author(s). 2020 Open Access This article is licensed under a Creative Commons Attribution 4.0 International License, which permits use, sharing, adaptation, distribution and reproduction in any medium or format, as long as you give appropriate credit to the original author(s) and the source, provide a link to the Creative Commons licence, and indicate if changes were made. The images or other third party material in this article are included in the article's Creative Commons licence, unless indicated otherwise in a credit line to the material. If material is not included in the article's Creative Commons licence and your intended use is not permitted by statutory regulation or exceeds the permitted use, you will need to obtain permission directly from the copyright holder. To view a copy of this licence, visit http://creativecommons.org/licenses/by/4.0/. The Creative Commons Public Domain Dedication waiver (http://creativecommons.org/publicdomain/zero/1.0/) applies to the data made available in this article, unless otherwise stated in a credit line to the data. 


\section{Background}

Henoch-Schönlein purpura (HSP), also known as IgA vasculitis, is the most common systemic vasculitis in children [1], with an incidence of 20 cases per 100,000 children annually [2]. HSP is considered a self-limiting disease; however, the long-term prognosis depends on the severity of renal involvement [3]. Renal involvement, particularly HSP nephritis (HSPN), may occur in 34\% of HSP children [4], although most children with HSPN have the opportunity to recover completely. HSPN may progress to renal failure in 2 to $20 \%$ of individuals $[5,6]$.

As the clinical symptoms and signs of HSPN vary greatly, it is difficult to predict the outcome and severity of HSPN [7]. Renal biopsy is the gold standard for evaluating the severity and prognosis of HSPN. Certain pathological features may be of value in predicting the prognosis of HSPN [7]. The existence of crescents is a prominent histological feature of HSPN and constitutes the basis of the pathological classification promulgated by the International Study of Kidney Disease in Children (ISKDC). Renal biopsy histological grade (grades I-II vs. grades III-V) score based on crescentic ISKDC pathological classification strongly predicts the prognosis of children with HSPN [8]. Also, in children, crescentic nephritis (ISKDC grades III-V) is considered an important risk factor for poor prognosis of HSPN [9-11]. Studies have reported the risk factors of renal involvement in HSP $[12,13]$. However, the discovery of risk factors for progression to crescentic HSPN (ISKDC grades III-V) is an important issue for children with HSP with known renal involvement. To the best of our knowledge, risk factors in children for progression to crescentic HSPN have not been reported.

\section{Methods}

\section{Patients}

This study is a single-center, retrospective study of 191 children under the care of the Department of Nephrology and Immunology of the Children's Hospital of Soochow University from January 2016 to October 2019. A patient was diagnosed with HSP in the presence of palpable purpura with lower limb predominance (mandatory criterion), along with one of following symptoms: abdominal pain; arthralgia or arthritis; renal involvement; and IgA deposition on histopathology [14]. The diagnosis of HSPN was by clinical presence of hematuria and/ or proteinuria within 6 months of the course of HenochSchönlein purpura [15]. Hematuria was classified as either gross hematuria or microscopic hematuria ( $\geq$ five red blood cells/high power microscopic field three times a week). Proteinuria was diagnosed based on any of the following criteria: (1) routine urine qualitative analysis showing positive urine protein three times within 1 week; (2) 24-h urine protein quantification $>150 \mathrm{mg}$ or urinary protein/creatinine $(\mathrm{mg} / \mathrm{mg})>0.2$; or (3) a urine microalbumin above normal, three times within 1 week.

Renal biopsy and pathological examination were performed to confirm the diagnosis of HSPN and to determine the severity of renal injury. Clinical treatment was carried out according to the Kidney Disease Improving Global Outcomes (KDIGO) guidelines [15, 16]. All the patients hospitalized with HSPN were preliminarily discharged after active treatment and after their clinical symptoms and signs were under control. Next, they were followed up via outpatient services every 2 weeks or once a month depending on the level of proteinuria until their condition was under control. HSPN patients with crescent formation were treated with glucocorticoids combined with cyclophosphamide pulse therapy, once per month, routinely. The renal outcomes of patients with HSPN during hospitalization are listed in the Supplementary text.

The study protocol was approved by the Institutional Ethics Review Committee at the Children's Hospital of Soochow University and the supervising local health ministry. Written informed consent was obtained from the legal surrogates of the subjects following a detailed description of the purpose of the study.

\section{Procedures}

Data collection included demographic data, clinical manifestations, laboratory data and renal biopsy characterization. Demographic data included the gender, age, and weight of the patients. Information about clinical manifestations, including joint pain, abdominal pain, recurrence of skin rash and HSP, season during diagnosis, food intolerance, and history of recent upper respiratory tract infection, were collected. Blood samples were collected to test the following components: whole blood cell counts and C-reactive protein (CRP) level; standard blood and biochemistry studies for renal function indicators (such as serum uric acid, blood urea nitrogen, and serum creatinine), complement and immunoglobulin levels, lymphocyte subset assessment (such as CD3+, CD4+/CD8+), coagulation spectrum, total cholesterol and triglyceride, and anti-streptolysin $\mathrm{O}$ and mycoplasma immunoglobulin level determination. Additionally, urine samples were obtained for white blood (WBC) and red blood cell (RBC) counts, as well as protein and creatinine quantitation. Among urinary protein levels, in addition to the urinary microalbumin/creatinine ratio (ACR), we analyzed several sensitive indicators of early renal damage: $\mathrm{N}$-acetylglucosaminidase (NAG), microglobulin and urinary transferrin (TRU) [17]. Proteinuria was measured after $24 \mathrm{~h}$ urine collection, and defined as protein excretion $150 \mathrm{mg}$. Also, urine samples were investigated using positive dipstick test with qualitative examination of levels of urinary occult blood and protein 
( - to +++$)$. Urinary WBC and RBC counts were tested using the urine sediment count method. Additionally, stools were tested for occult blood using the colloidal gold immunological method to monitor gastrointestinal involvement. This study had quantitative and qualitative variable data for 52 possible indicators.

All renal biopsy specimens were examined by light microscopy and immunofluorescence. Specimens were read by two pathologists (a chief physician and a deputy chief physician) who remained blind to clinical history and laboratory data. Two physicians, the chief in the department of pediatric nephrology and immunology, graded the pathological results. The biopsy results were graded according to the classification of the ISKDC [18]: (I) minimal alterations; (II) mesangial proliferation; (IIIa) focal or (IIIb) diffuse proliferation or sclerosis with < $50 \%$ crescents; (IVa) focal or (IVb) diffuse mesangial proliferation or sclerosis with $50-75 \%$ crescents; (Va) focal or $(\mathrm{Vb})$ diffuse mesangial proliferation or sclerosis with $>75 \%$ crescents; and (VI) membranoproliferativelike lesions.

\section{Statistical analysis}

Univariate statistical analyses were performed using Statistics Analysis System (SAS) software version 9.2 (SAS Institute Inc., Cary, NC, USA). Variable data were grouped according to two histopathological categories: those without glomerular crescent formation (ISKDC grades I-II) and those with glomerular crescent formation (ISKDC grades III-V). The quantitative data were analyzed using $t$-Test (homogeneity of variance) or Wilcoxon rank-sum test (heterogeneity of variance). The chi-square or Fisher's exact test (dichotomous data) and the Wilcoxon two-sample test (multi-categorical data) were carried out on the qualitative data. Stepwise logistic regression analysis, performed on SAS 9.2, was used for multivariate analysis to assess the risk factors for crescentic HSPN. The odds ratios (OR) and the 95\% confidence intervals (CI) were calculated. The diagnostic efficacy of the logistic regression model was evaluated by the receiver operating characteristic curve (ROC) and the Hosmer and Lemeshow goodness-of-fit test. The confidence interval was $95 \%$, and for all tests the level of statistical significance was defined as 0.05 .

\section{Results}

A total of 191 children with HSPN received their first renal biopsy as part of this study, which included 107 (56\%) males and 84 females (44\%), with a median age of 7 years (range: $2-15$ years). According to ISKDC criteria, subjects were divided into two groups: those without glomerular crescent formation (ISKDC grades I-II, $n=$ 146 cases) and those with glomerular crescent formation (ISKDC grades III-V, $n=45$ cases). All patients in the crescent group were ISKDC grade IIIa-IIIb, which accounted for $23.56 \%$ of the total number of cases. There were no individuals classified as ISKDC grades IV-VI.

Among the 52 variables assessed by univariate analysis, there were significant differences in 18 variables between the two groups. The variables in the qualitative data set were abdominal pain, repeated rash more than three times at diagnosis, urinary occult blood, and urinary protein levels (Table 1). The variables in quantitative data were $\mathrm{C}$ reactive protein, WBC, platelet, complement component 3 , total cholesterol, triglyceride levels, 24-h urinary microalbumin, 24-h urinary total protein, urinary RBC count, urinary WBC count, N-acetylglucosaminidase (NAG), $\alpha 1$ -

Table 1 Univariate analysis of the factors associated with qualitative data in HSPN patients with and without crescent formation

\begin{tabular}{|c|c|c|c|c|}
\hline Variable & Grade I-II $n=146$ & Grade III-V $n=45$ & $\mathrm{x}^{2}$ & $\mathbf{P}$ \\
\hline Gender, Male/Female & $79 / 67$ & $28 / 17$ & 0.9033 & 0.3491 \\
\hline Age, $\geq 8 /<8$ years & $87 / 59$ & $28 / 17$ & 0.0414 & 0.8389 \\
\hline Age, $\geq 10 /<10$ years & $50 / 96$ & $17 / 28$ & 0.0786 & 0.7792 \\
\hline Food intolerance, Severe/<Severe & $51 / 80$ & $16 / 24$ & 0.0147 & 0.9035 \\
\hline Upper respiratory tract infection, Yes/No & $22 / 118$ & $11 / 34$ & 1.7709 & 0.1833 \\
\hline Joint pain, Yes/No & $60 / 82$ & $20 / 24$ & 0.1404 & 0.7079 \\
\hline Abdominal pain, Yes/No & $46 / 96$ & $25 / 20$ & 7.7830 & 0.0053 \\
\hline Occult blood in stool, Yes/No & $40 / 103$ & $17 / 27$ & 1.8058 & 0.1790 \\
\hline Recurrence of HSP, Yes/No & $22 / 120$ & $12 / 33$ & 2.8679 & 0.0904 \\
\hline Season, Winter-Sping/Summer-Autumn & $80 / 65$ & $23 / 22$ & 0.2282 & 0.6329 \\
\hline Recurrence of skin rash, $\geq 3 /<3$ times & 9/136 & $7 / 39$ & 3.6940 & $0.0383^{*}$ \\
\hline Recurrence of skin rash, Yes/No & $61 / 84$ & $26 / 19$ & 3.4140 & 0.0646 \\
\hline Level of urinary protein, $-/+/++/+++$ & $81 / 32 / 28 / 5$ & $1 / 8 / 18 / 18$ & 61.1805 & $<0.0001$ \\
\hline Level of urinary occult blood, $-/+/++/+++$ & $14 / 39 / 58 / 35$ & $1 / 5 / 10 / 29$ & 21.6862 & $<0.0001$ \\
\hline
\end{tabular}

"Fisher's exact test 
microglobulin, urinary transferrin (TRU), and urinary ACR (Table 2).

After multivariate logistic regression analysis, urinary WBC count $(O R=3.300 ; 95 \% \mathrm{CI} ; 1.119-9.739 ; P=0.0306)$ and urinary $\mathrm{ACR}(\mathrm{OR}=25.053$; 95\% CI, 1.354-463.708;
$P=0.0305)$ were found to be independent risk factors for glomerular crescentic renal damage (Table 3). The area under the ROC (AUC) of urinary WBC and ACR were 0.753 and 0.698 , respectively (Fig. 1), with the Hosmer and Lemeshow goodness-of-fit test $(P=0.0669, P>0.05)$.

Table 2 Univariate analysis of the factors associated with quantitative data in HSPN patients with and without crescent formation

\begin{tabular}{|c|c|c|c|}
\hline Variables & Grade I-II $n=146$ & Grade III-V $n=45$ & $P$ \\
\hline C-reactive protein, mg/l & $3.6629 \pm 8.0603$ & $6.5598 \pm 11.712$ & $0.0307^{*}$ \\
\hline White blood cell count, $\times 10^{9} / 1$ & $10.029 \pm 4.0135$ & $11.723 \pm 3.8933$ & 0.0135 \\
\hline Lymphocyte, \% & $28.412 \pm 12.924$ & $24.107 \pm 13.352$ & 0.0540 \\
\hline Platelet count, $\times 10^{9} / /$ & $309.17 \pm 88.675$ & $343.07 \pm 82.524$ & 0.0239 \\
\hline Complement component 3, g/l & $1.1476 \pm 0.1881$ & $1.2171 \pm 0.1938$ & 0.0330 \\
\hline Complement component 4, g/l & $0.2555 \pm 0.0857$ & $0.2822 \pm 0.0875$ & 0.0707 \\
\hline Immunoglobulin A, g/l & $2.2246 \pm 0.8366$ & $2.3653 \pm 0.8168$ & 0.3237 \\
\hline Immunoglobulin G, g/l & $9.601 \pm 2.495$ & $9.1013 \pm 2.3659$ & 0.2371 \\
\hline Immunoglobulin M, g/l & $1.181 \pm 0.5038$ & $1.2353 \pm 0.5734$ & 0.5425 \\
\hline Total cholesterol, mmol/l & $4.2461 \pm 1.2149$ & $5.1396 \pm 1.5511$ & $<0.0001$ \\
\hline Triglyceride, mmol/l & $1.2288 \pm 0.7094$ & $1.6627 \pm 0.9239$ & $0.0006^{*}$ \\
\hline Serum uric acid, mmol/l & $267.91 \pm 83.918$ & $266.55 \pm 78.065$ & 0.9232 \\
\hline Blood urea nitrogen, $\mathrm{mmol} / \mathrm{l}$ & $4.4997 \pm 1.2614$ & $4.6858 \pm 1.4228$ & 0.4031 \\
\hline Serum creatinine, mmol/l & $39.261 \pm 10.863$ & $38.998 \pm 8.1706$ & $0.7791^{*}$ \\
\hline $\mathrm{CD} 4+/ \mathrm{CD} 8+, \%$ & $1.1854 \pm 0.3808$ & $1.1422 \pm 0.4351$ & 0.5220 \\
\hline $\mathrm{CD} 3+, \%$ & $67.1528 \pm 10.3439$ & $66.1283 \pm 9.3301$ & 0.5504 \\
\hline $\mathrm{CD} 3+\mathrm{CD} 4+, \%$ & $32.488 \pm 7.649$ & $31.087 \pm 8.6809$ & 0.3005 \\
\hline $\mathrm{CD} 3+\mathrm{CD} 8+, \%$ & $28.1910 \pm 6.1454$ & $28.9500 \pm 6.2194$ & 0.4680 \\
\hline $\mathrm{CD} 19+\mathrm{CD} 23+, \%$ & $9.0250 \pm 3.8344$ & $8.6178 \pm 3.6392$ & 0.5300 \\
\hline Mycoplasma lgG, AU/I & $68.3077 \pm 65.7568$ & $71.9142 \pm 73.0422$ & 0.7652 \\
\hline Mycoplasma IgM, COL & $1.0552 \pm 0.8047$ & $1.0084 \pm 0.6630$ & 0.7329 \\
\hline Anti-streptolysin O, IU/ml & $161.0 \pm 264.4$ & $150.0 \pm 141.8$ & $0.1712^{*}$ \\
\hline $24 \mathrm{~h}$ urinary microalbumin, mg & $269.2 \pm 293.6$ & $565.7 \pm 330.4$ & $<0.0001$ \\
\hline $24 \mathrm{~h}$ urinary total protein, mg & $542.32 \pm 821.84$ & $1799.5 \pm 1778.9$ & $<0.0001$ \\
\hline Urinary RBC count, /UL & $94.49 \pm 233.54$ & $630.65 \pm 1505.9$ & $<0.0001^{*}$ \\
\hline Urinary WBC count, /UL & $20.255 \pm 63.389$ & $80.811 \pm 132.25$ & $<0.0001^{*}$ \\
\hline $\mathrm{N}$-acetylglucosaminidase, U/L & $26.003 \pm 16.885$ & $34.677 \pm 33.282$ & $0.0310^{*}$ \\
\hline a1-Microglobulin, U/L & $7.359 \pm 4.9073$ & $9.333 \pm 5.0892$ & 0.0204 \\
\hline ß2-Microglobulin, U/L & $0.3357 \pm 0.4068$ & $0.3231 \pm 0.1824$ & $0.5001^{*}$ \\
\hline Urinary transferrin, mg/l & $24.014 \pm 34.348$ & $75.179 \pm 42.057$ & $<0.0001^{*}$ \\
\hline Urinary microalbumin/creatinine, mg/mg & $0.2835 \pm 0.2725$ & $0.7933 \pm 0.5126$ & $<0.0001^{*}$ \\
\hline Prothrombin time, $\mathrm{s}$ & $12.698 \pm 1.2648$ & $12.293 \pm 1.3303$ & 0.0659 \\
\hline D-dimer, $\mu \mathrm{g} / \mathrm{l}$ & $928.71 \pm 1645.2$ & $1177.3 \pm 1941.1$ & 0.4177 \\
\hline Fibrinogen, g/l & $2.5638 \pm 0.7827$ & $2.7704 \pm 0.9135$ & 0.1394 \\
\hline Antithrombin III, \% & $110.97 \pm 17.292$ & $109.79 \pm 22.1$ & $0.7695^{*}$ \\
\hline Thrombin time, s & $17.732 \pm 1.72$ & $17.704 \pm 1.9175$ & 0.9275 \\
\hline Activated partial thrombin time, $s$ & $32.706 \pm 7.7257$ & $30.46 \pm 8.4283$ & 0.0975 \\
\hline Weight, kg & $32.762 \pm 12.69$ & $34.611 \pm 14.598$ & 0.4110 \\
\hline
\end{tabular}

"The variance of the two samples is uneven, and the nonparametric rank sum test is used 
Table 3 Logistic analysis of the risk factors in HSPN patients with crescent formation

\begin{tabular}{|c|c|c|}
\hline Variable & OR $(95 \% \mathrm{Cl})$ & $P$ value \\
\hline Abdominal pain & $2.119(0.770-5.833)$ & 0.1459 \\
\hline Recurrence of skin rash $\geq 3$ times & $2.050(0.339-12.385)$ & 0.4341 \\
\hline C-reactive protein & $0.990(0.241-4.069)$ & 0.9890 \\
\hline White blood cell count & $1.288(0.423-3.922)$ & 0.6561 \\
\hline Platelet count & $1.153(0.359-3.698)$ & 0.8113 \\
\hline Complement component 3 & $13.666(0.205-912.816)$ & 0.2225 \\
\hline Total cholesterol & $1.530(0.523-4.479)$ & 0.4377 \\
\hline Triglyceride & $1.920(0.567-6.501)$ & 0.2943 \\
\hline $24 \mathrm{~h}$ urinary microalbumin & $>999.999(<0.001->999.999)$ & 0.9520 \\
\hline $24 \mathrm{~h}$ urinary total protein & $<0.001(<0.001->999.999)$ & 0.9374 \\
\hline Urinary RBC count & $6.577(0.646-66.966)$ & 0.1116 \\
\hline Urinary WBC count & 3.300 (1.119-9.739) & 0.0306 \\
\hline $\mathrm{N}$-acetylglucosaminidase & $1.799(0.147-21.969)$ & 0.6456 \\
\hline a1-Microglobulin & $1.856(0.556-6.196)$ & 0.3149 \\
\hline Urinary transferrin & $1.086(0.054-21.903)$ & 0.9572 \\
\hline Level of urinary occult blood & $1.749(0.040-76.622)$ & 0.7720 \\
\hline Level of urinary protein & > $999.999(<0.001->999.999)$ & 0.9400 \\
\hline Urine microalbumin/creatinine & $25.053(1.354-463.708)$ & 0.0305 \\
\hline
\end{tabular}

\section{Discussion}

In this retrospective study, risk factors were determined between pediatric patients with HSPN who had or did not have renal crescent formation (ISKDC grade $\geq$ III versus ISKDC grade $<$ III). Multivariate logistic analysis showed that urinary WBC count and urinary ACR were independent risk factors for crescent formation. To the best of our knowledge, these risk factors have not previously been identified in relation to pediatric HSPN.

Our study has focused on the risk factors in pediatric patients with HSPN, as crescent formation has shown to be a poor prognostic factor [7-10]. However, there have been reports that found that histopathological findings also have poor predictive value for the prognosis of HSPN [19, 20]. Koskela et al. [19] reported the value of follow up renal biopsies in prognosis assessment from 26 patients with HSPN, and they concluded that followup biopsies provide limited additional information beyond clinical symptoms in HSPN outcome prediction. At the same time, results based on the Oxford classification revealed that complement $\mathrm{C} 1-2$ showed differences in diagnostic biopsies between the two groups, supporting results that active treatment should be commenced before fibrosis of crescents; our results also supporting this finding. We found that clinical manifestations, such as abdominal pain and recurrence of skin rash more than three times, were different between HSPN patients with and without crescents; however, they were not independent risk factors for crescent formation. Our

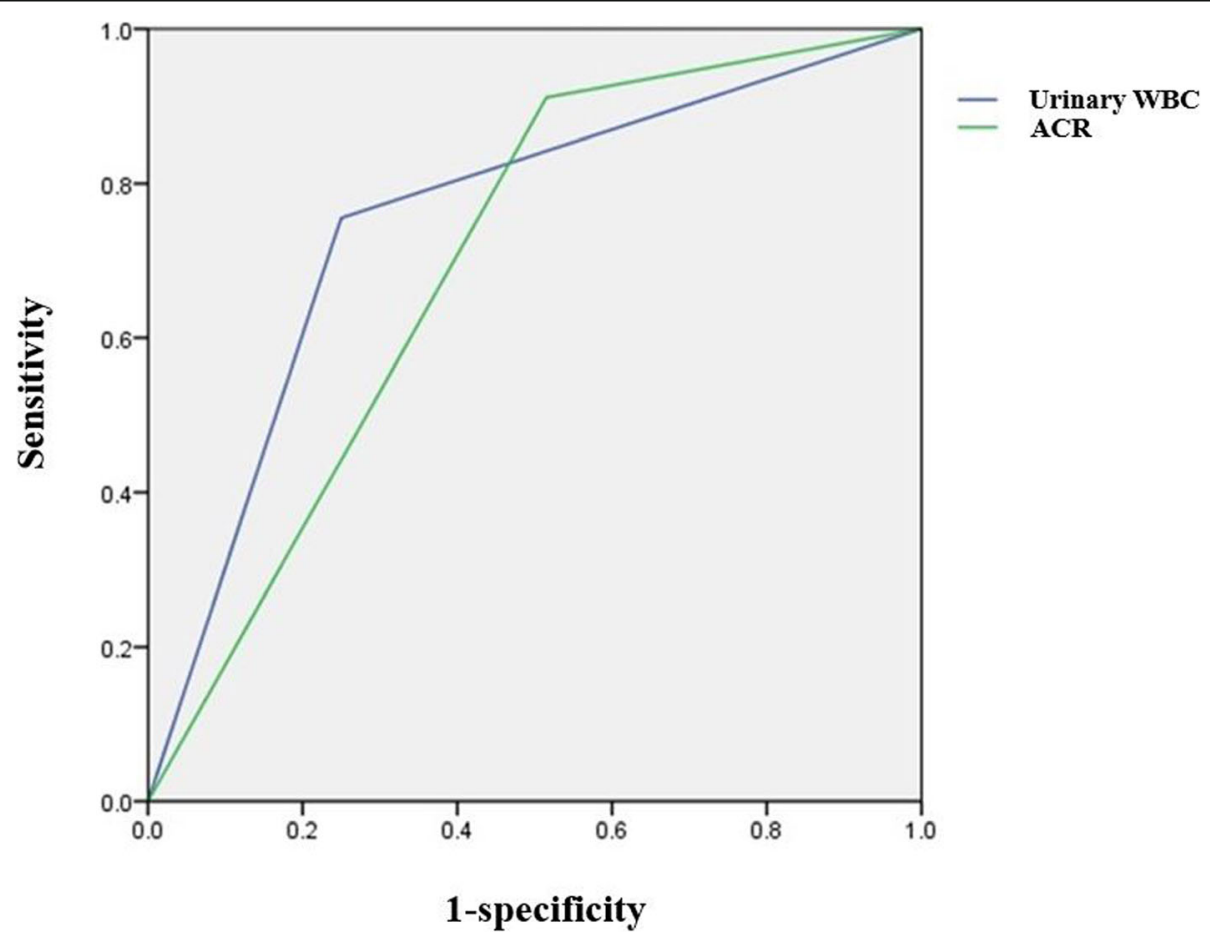

Fig. 1 ROC curve to evaluate the diagnostic efficiency of the model. Area under the curve $=0.753$ and 0.698 , respectively 
results are consistent with study of Soylemezoglu et al. [20], in that clinical findings do not seem to predict the outcome of HSP nephritis in children. They concluded that the presence of crescents in the first biopsy did not seem to predict the outcome of HSPN in children.

Proteinuria denotes severe renal injury, and proteinuria at the time of symptom onset was associated with poor prognosis $[8,21]$. This is consistent with our study, where multiple proteinuria indicators of renal function were associated with crescent formation, based on our univariate analysis (Tables 1 and 2). However, based on logistic regression analysis, only urinary ACR was found to be independent risk factor for predicting crescentic glomerulonephritis (ISKDC grades III-V). ACR is a sensitive indicator of glomerular damage with high specificity [22]. Significant elevation in 24-h urinary protein levels and urinary protein/creatinine ratio were found in ISKDC grades IIb, IIIa, and IIIb HSPN patients compared to ISKDC grade I and IIa subjects (the area under the ROC curve was 0.767 and 0.731 , respectively), suggesting that 24-h urinary protein levels and urinary protein/creatinine ratio may predict the pathological classification of HSPN [23], supporting the view that the severity of clinical manifestations in HSPN is related to the formation of crescents [10]. Other studies employed log-term follow-up to assess renal outcome in children with HSPN. 24-h proteinuria was associated with poor prognosis [21]. Additionally, multivariate analysis showed that patients with poor prognosis had a higher urinary albumin/creatinine ratio after 17 years of followup [8].

Increased urinary WBCs are an indicator of renal injury. Urinary WBCs with positivity defined as more than 10 cells per high power microscopic field [24], positively correlated with complement C3 in HSPN subjects, suggesting that the complement system is involved in promoting renal injury [23]. Complement-leukocytedependent interactions cause glomerular damage. Indeed, data indicate that in HSP subjects, WBCs may incite renal vasculitis [25]. In children with HSP, increased peripheral blood leukocyte and neutrophil counts were risk factors for small vessel injury and kidney involvement [26]. Analysis of HSPN patient samples and renal biopsies from animals with experimental HSPN found that WBCs participated in crescent formation [7]. WBC count, CRP, and humoral immune complement $\mathrm{C} 3$ levels were identified risk factors for crescentic nephritis in this study. Additionally, cytokine-driven neutrophilia was associated with epithelial cell proliferation and fibrosis in Bowman's space [7]. Nevertheless, in Jang's study, the authors concluded that the activation of the complement system does not correlate with the clinical or pathological severity of HSPN [27]. They compared the differences in pathologic findings of 35 children and 12 adults with HSPN according to C4d positivity in groups, while our results revealed that the $\mathrm{C} 3$ complement of the complement system is involved in promoting renal injury. In addition, the differences between the two studies may be due to the application of different study groups, and different sample sizes.

Of further novelty, we found that abdominal pain and recurrence of skin rash more than three times were possible risk factors for the formation of HSPN crescents. Again, to the best of our knowledge, such associations have not been reported previously. Other studies noted that abdominal pain and persistent purpura ( $>1$ month) were risk factors for pediatric HSPN [28]; purpura relapses more than four times predicted a poor prognosis of HSPN [29]. Repeated rashes in the setting of HSPN may indicate increased inflammation/neutrophilia and vasculitis.

Hematuria is one of the initial renal manifestations of HSPN [15]. Urinary red blood cell count and level of urinary occult blood were possible risk factors in our study. The published data in this regard is mixed. For example, a meta-analysis showed that hematuria and mild proteinuria with hematuria were associated with better prognosis [11]. In contrast, patients with isolated hematuria or mild albuminuria at the onset of the disease had adverse consequences [30]. These conflicting reports may be due to different treatment schemes. For example, the current strategy for HSPN treatment is mostly based on the KDIGO guidelines [16], but some experts have pointed out that the current treatment schemes for HSPN are insufficient if only the KDIGO guidelines are followed, especially for mild types of HSPN [31].

Finally, few studies have shown that platelets are involved in the process of renal injury [32]. We found that platelet count, total cholesterol, and triglyceride levels were likely risk factors for crescent formation in pediatric HSPN. All these related indexes need to be further clarified in terms of their role in the pathogenesis and the prognosis of HSP and HSPN.

There are limitations to our study. First, the study was the from a single center and the sample size studied was small. Second, further detailed classification the pathological characteristics of the glomerular crescent (cellular, cellular-fibrous, and fibrous crescent) was not completed. This is important as it may affect the accuracy of the results. In addition, our study did not assess the risk of variables in relation to other pathologic classifications such as the Oxford classification (MEST-C) and the semi-quantitative classification (SQC), all of which are reported studies in HSPN [19]. Lastly, tissue assessment was not complemented with a control group of pediatric patients with renal disease. Thus, it is not clear if the pathologic lesions and risk factor associations are limited only to HSPN. 


\section{Conclusions}

Results presented herein find that, in pediatric HSPN, increased urinary WBCs and/or urinary ACR are risk factors for worse renal pathology. In the setting of HSPN, such laboratory findings may warrant increased treatment intervention by specialists to limit renal damage.

\section{Supplementary Information}

The online version contains supplementary material available at https://doi. org/10.1186/s12887-020-02404-2.

Additional file 1: Supplemental Table 1. The matched $t$-test was performed between urinary ACR tested before biopsy and after active treatment, followed by discharge of patients from the hospital.

\section{Abbreviations}

HSPN: Henoch-Schönlein purpura nephritis; ISKDC: International Study of Kidney Disease in Children; WBC: White blood cell; ACR: Microalbumin/ creatinine ratio; HSP: Henoch-Schönlein purpura; KDIGO: Kidney Disease Improving Global Outcomes; CRP: C-reactive protein; RBC: Red blood cell; OR: Odds ratios; Cl: Confidence intervals; ROC: The receiver operating characteristic curve; NAG: N-acetylglucosaminidase; TRU: Urinary transferrin; AUC: The area under the ROC; C3: Complement component 3; SQC: The semiquantitative classification

\section{Acknowledgements}

The authors would like to thank Fang Fang of Pediatric Research Institute of Soochow University for assistance in the statistical analyses.

\section{Authors' contributions}

YRS made a contribution to the concept and design, acquisition, analysis of data and drafted the article. WLG, MS and XZL made a contribution of concept, design, analysis and interpretation of data, and critically revised the overall content of the manuscript. QL, XMZ made a contribution of acquisition, analysis and critically revised the article. All authors read and approved the final manuscript.

\section{Funding}

This work was supported by the following: Suzhou Science and Technology Plan Project in 2018, Key Laboratory for Diagnosis and Treatment of Children's Immune Diseases in Suzhou (SSZ201808), Key Laboratory of Children Kidney Pathology in Suzhou (SZS201511). The funders had no role in study design, data collection and analysis, decision to publish, or preparation of the manuscript.

\section{Availability of data and materials}

The datasets used and/or analyzed during the current study are available from the corresponding author on reasonable request.

\section{Ethics approval and consent to participate}

The study protocol was approved by the Institutional Ethics Review Committee at the Children's Hospital of Soochow University and the supervising local health ministry. Written informed consent was obtained from the legal surrogates of the subjects following a detailed description of the purpose of the study.

\section{Consent for publication}

Not applicable.

\section{Competing interests}

The authors declare that they have no competing interests.

\section{Author details}

'Department of Radiology, Children's Hospital of Soochow University, 92 Zhongnan Street, Suzhou 215025, Jiangsu, China. ${ }^{2}$ Department of Nephrology and Immunology, Children's Hospital of Soochow University, 303
Jingde Road, Suzhou 215003, Jiangsu, China. ${ }^{3}$ Department of Pathology, Children's Hospital of Soochow University, 92 Zhongnan Street, Suzhou 215025, Jiangsu, China.

Received: 9 May 2020 Accepted: 26 October 2020

Published online: 02 November 2020

\section{References}

1. Jennette JC. Overview of the 2012 revised international Chapel Hill consensus conference nomenclature of vasculitides. Clin Exp Nephrol. 2013; 17(5):603-6.

2. Gardner-Medwin JM, Dolezalova P, Cummins C, Southwood TR. Incidence of Henoch-Schonlein purpura, Kawasaki disease, and rare vasculitides in children of different ethnic origins. Lancet. 2002;360:1197-202.

3. Ronkainen J, Nuutinen $\mathrm{M}$, Koskimies $\mathrm{O}$. The adult kidney 24 years after childhood Henoch-Schönlein purpura: a retrospective cohort study. Lancet. 2002;360:666-70.

4. Narchi H. Risk of long term renal impairment and duration of follow up recommended for Henoch-Schönlein purpura with normal or minimal urinary findings: a systematic review. Arch Dis Child. 2005;90:916-20.

5. Stewart M, Savage JM, Bell B, McCord B. Long term renal prognosis of Henoch- Schönlein Purpura in an unselected childhood population. Eur 」 Pediatr. 1988;147(2):113-5.

6. Ronkainen J, Ala-Houhala M, Huttunen NP, Jahnukainen T, Koskimies $\mathrm{O}$ Ormälä T, Nuutinen M. Outcome of Henoch-Schoenlein nephritis with nephrotic-range proteinuria. Clin Nephrol. 2003;60(2):80-4.

7. Davin JC. Henoch-Schönlein Purpura nephritis: pathophysiology, treatment, and future strategy. Clin J Am Soc Nephrol. 2011;6(3):679-89.

8. Edström Halling S, SöDerberg MP, Berg UB. Predictors of outcome in Henoch-Schönlein nephritis. Pediatr Nephrol. 2010;25(6):1101-8.

9. Goldstein AR, White RH, Akuse R, Chantler C. Long-term follow-up of childhood Henoch-Schönlein nephritis. Lancet. 1992;339:280-2.

10. Szeto CC, Choi PC, To KF, Li PK, Hui J, Chow KM, Leung CB, Lui SF, MacMoune LF. Grading of acute and chronic renal lesions in Henoch-Schönlein purpura. Mod Pathol. 2001;14:635-40.

11. Shi D, Chan H, Yang $X$, Zhang G, Yang H, Wang M, Li Q. Risk factors associated with IgA vasculitis with nephritis (Henoch-Schönlein purpura nephritis) progressing to unfavorable outcomes: a meta-analysis. PLoS One. 2019;14(10):e0223218

12. Chan H, Tang YL, Lv XH, Zhang GF, Wang M, Yang HP, Li Q. Risk factors associated with renal involvement in childhood Henoch-Schönlein Purpura: a meta-analysis. PLoS One. 2016;11(11):e0167346.

13. Buscatti IM, Casella BB, Aikawa NE, Watanabe A, Farhat SCL, Campos LMA, Silva CA. Henoch-Schönlein purpura nephritis: initial risk factors and outcomes in a Latin American tertiary center. Clin Rheumatol. 2018;37:131924.

14. Ozen S, Pistorio A, lusan SM, Bakkaloglu A, Herlin T, Brik R, Buoncompagni A, Lazar C, Bilge I, Uziel Y, et al. EULAR/PRINTO/PRES criteria for HenochSchönlein purpura, childhood polyarteritis nodosa, childhood Wegener granulomatosis and childhood Takayasu arteritis: Ankara 2008. Part II: final classification criteria. Ann Rheum Dis. 2010;69(5):798-806.

15. Subspecialty Group of Renal Diseases, the Society of Pediatrics, Chinese Medical Association. Evidence-based guideline for diagnosis and treatment of Henoch-Schönlein purpura nephritis (2016) (in Chinese). Chin J Pediatr. 2017:55(9):647-51.

16. Kidney Disease: Improving Global Outcomes (KDIGO) Glomerulonephritis Work Group. KDIGO Clinical Practice Guideline for Glomerulonephritis. Chapter 11: Henoch-Schönlein purpura nephritis. Kidney Int Suppl. 2012;2: 218-20.

17. Khan NU, Lin J, Liu XK, Li H, Lu W, Zhong Z, Zhang H, Waqas M, Shen L. Insights into predicting diabetic nephropathy using urinary biomarkers. Biochim Biophys Acta, Proteins Proteomics. 2020;1868:140475.

18. Counahan $\mathrm{R}$, Winterborn MH, White $\mathrm{RH}$, Heaton JM, Meadow SR, Bluett NH, Swetschin H, Cameron JS, Chantler C. Prognosis of Henoch-Schönlein nephritis in children. Br Med J. 1977;2(6078):11-4.

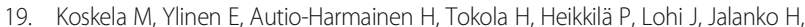
Nuutinen M, Jahnukainen T. Prediction of renal outcome in Henoch-Schönlein nephritis based on biopsy findings. Pediatr Nephrol. 2020;35:659-68.

20. Soylemezoglu O, Ozkaya O, Ozen S, Bakkaloglu A, Dusunsel R, Peru H, Cetinyurek A, Yildiz N, Donmez O, Buyan N, et al. Henoch-Schönlein nephritis: a nationwide study. Nephron Clin Pract. 2009;112:C199-204. 
21. Koskela M, Ylinen E, Ukonmaanaho EM, Autio-Harmainen H, Heikkilä P, Lohi J, Jauhola O, Ronkainen J, Jahnukainen T, Nuutinen M. The ISKDC classification and a new semiquantitative classification for predicting outcomes of Henoch-Schönlein purpura nephritis. Pediatr Nephrol. 2017; 32(7):1201-9.

22. Handelsman $Y$, Bloomgarden ZT, Grunberger G, et al. American association of clinical endocrinologists and American college of endocrinology - clinical practice guidelines for developing a diabetes mellitus comprehensive care plan - 2015. Endocr Pract. 2015;21(Supplement 1):1-87.

23. Ye Q, Shang $S, A m L$, Zhang T, Shen HQ, Chen XJ, Mao JH. 24h Urinary Protein Levels and Urine Protein/Creatinine Ratios Could Probably Forecast the Pathological Classification of HSPN. PLoS One. 2015;10(5):e0127767.

24. Mori R, Yonemoto N, Fitzgerald A, Tullus K, Verrier-Jones K, Lakhanpaul M. Diagnostic performance of urine dipstick testing in children with suspected UTI: a systematic review of relationship with age and comparison with microscopy. Acta Paediatr. 2010;99:581-4.

25. Ece A, Kelekçi S, Hekimoğlu A, Kocamaz H, Balik H, Yolbaş I, Erel O. Neutrophil activation, protein oxidation and ceruloplasmin levels in children with Henoch-Schönlein purpura. Pediatr Nephrol. 2007;22(8):1151-7.

26. Nagamori T, Oka H, Koyano S, Takahashi H, Oki J, Sato Y, Murono K, Iseki K, Takeguchi R, Takeda T, et al. Construction of a scoring system for predicting the risk of severe gastrointestinal involvement in Henoch-Schönlein Purpura. Springerplus. 2014;3:171

27. Jang HM, Baek H, Han MH, Kim YJ, Kim CD, Kim YL, Park SH, Cho MH. Activation of Complement System in Henoch-Schönlein Purpura Nephritis. Fetal Pediatr Pathol. 2020;13:1-8. https://doi.org/10.1080/15513815.2020. 1761914.

28. Shin Jl, Park JM, Shin YH, Hwang DH, Kim JH, Lee JS. Predictive factors for nephritis, relapse, and significant proteinuria in childhood HenochSchönlein purpura. Scand J Rheumatol. 2006;35(1):56-60.

29. Lucas GJ, Alvarez BO, Sanahuja Ibáñez MJ, Ortega López PJ, Zamora MI. Outcome of Henoch-Schönlein nephropathy in pediatric patients. Prognostic factors. Nefrologia. 2008;28:627-32.

30. Tudorache E, Azema C, Hogan J, Wannous H, Aoun B, Decramer S, Deschênes $G$, Ulinski T. Even mild cases of paediatric Henoch-Schönlein purpura nephritis show significant long-term proteinuria. Acta Paediatr. 2015;104:843-8.

31. Delbet JD, Hogan J, Aoun B, Stoica I, Salomon R, Decramer S, Brocheriou I, Deschênes G, Ulinski T. Clinical outcomes in children with HenochSchönlein purpura nephritis without crescents. Pediatr Nephrol. 2017;32(7): 1193-9.

32. Suvorova TS, Tov NL, Movchan EA. Vessel-platelet and coagulation components of hemostasis in patients with chronic tubulointerstitial nephritis. Ter Arkh. 2007;79:56-60.

\section{Publisher's Note}

Springer Nature remains neutral with regard to jurisdictional claims in published maps and institutional affiliations.

Ready to submit your research? Choose BMC and benefit from:

- fast, convenient online submission

- thorough peer review by experienced researchers in your field

- rapid publication on acceptance

- support for research data, including large and complex data types

- gold Open Access which fosters wider collaboration and increased citations

- maximum visibility for your research: over $100 \mathrm{M}$ website views per year

At $\mathrm{BMC}$, research is always in progress.

Learn more biomedcentral.com/submissions 